\title{
Vulnerabilidades sociais e juvenil nos mananciais da zona sul da cidade de São Paulo
}

\author{
Elizabeth Borelli \\ Pontifícia Universidade Católica de São Paulo (PUC-SP)
}

\section{Vulnerabilidades sociais e juvenil nos mananciais da zona sul da cidade de São Paulo}

Resumo: Este artigo é um produto parcial da pesquisa "Reflexos da Vulnerabilidade Socioambiental nas Manifestações Musicais dos Jovens Paulistanos da Periferia", identificando como recorte geográfico a periferia da Zona Sul da cidade de São Paulo. Trata-se de uma região que começou a se formar devido à ocupação populacional desordenada em áreas de manancial, onde a vulnerabilidade social é agravada por situações de risco e degradação ambiental, dado o adensamento das áreas de favelas, configurando um processo de exclusão ambiental e urbana. Temporalmente, a pesquisa parte da década de 1980, quando se expande o padrão de extensão da periferia e surgem as manifestações culturais nas periferias dos grandes centros urbanos. Nesta reflexão, a relação entre política e cultura é apresentada através da análise dos mecanismos de sociabilidade que articulam os jovens afrodescendentes das periferias em torno de intervenções culturais coletivas, como formas de criação e reprodução da sua realidade social.

Palavras-chave: Vulnerabilidades sociais. Vulnerabilidade juvenil. Periferia. Mananciais. Transformações urbanas.

\section{Social Vulnerabilities and Youth in the Water Catchment Areas of the Southern Zone of the City of São Paulo}

Abstract: This article is a partial product of the study "Reflexes of the Socio-environmental Vulnerability in the Musical Manifestations of Paulista Youth from the Periphery," which focuses on the Southern Zone of the city of São Paulo. This is a region that took shape through the unordered occupation of water catchment areas, where social vulnerability is aggravated by situations of risk and environmental degradation, given the increased density of favela regions, establishing a process of environmental and urban exclusion. The study begins in the 1980s, when the pattern of extension of the periphery expanded and cultural manifestations arose in the peripheries of the large urban centers. In this reflection, the relationship between politics and culture is presented through the analysis of the mechanisms of sociability that articulate Afro-descendent youth from the periphery around collective cultural interventions, as forms of creation and reproduction of their social reality.

Keywords: Social vulnerabilities. Youth vulnerability. Periphery. Water catchment areas. Urban transformations. 


\section{Introdução}

Este artigo tem por objetivo analisar aspectos que tipificam a periferia da zona sul no contexto urbano da megalópole paulistana, como situações de degradação ambiental, segregação socioespacial, pobreza e altas vulnerabilidades sociais e juvenil. A pesquisa documental partiu de levantamentos realizados pela Fundação Sistema Estadual de Análise de Dados (SEADE) e pela Prefeitura Municipal de São Paulo, referentes à caracterização regional da periferia paulistana. Observa-se uma clara tendência de crescimento populacional no vetor sul, em função do processo de acumulação econômica e da especulação imobiliária que vêm empurrando as populações pobres para áreas cada vez mais distantes, como as de preservação ambiental e proteção de mananciais.

Nessa perspectiva, cabe uma reflexão teórica acerca de crescimento urbano e tendências socioespaciais da periferia, dado o intenso processo de expansão e periferização das favelas no município de São Paulo, onde residem os sujeitos da pesquisa.

O excepcional crescimento das cidades constituise em fenômeno mundial no final do século 20 e início do século 21. É o chamado fenômeno urbano, cuja maior expressão é o surgimento das "megacidades", com mais de 10 milhões de habitantes, caracterizando a população do mundo contemporâneo como majoritariamente urbana.

Castells (1983) analisa o fenômeno urbano vinculado à estrutura de uma sociedade, relacionando-o com novas formas de articulação social, provenientes do modo de produção capitalista e que tendem a ultrapassá-lo.

$\mathrm{O}$ crescimento urbano não se restringe a um mero aumento do número de pessoas que vivem nas cidades: uma das suas características determinantes é a concentração espacial. São, exatamente, as grandes cidades que apresentam um crescimento urbano mais rápido, implicando em problemas decorrentes mais relevantes.

Esta condição ocasiona uma série de novos e complexos problemas para a compreensão e a gestão do espaço nas sociedades urbanas, sendo que, aqueles de ordem socioambiental, encontram-se destacados no contexto das cidades, particularmente em países em condições socioeconômicas de alta complexidade, como é o caso do Brasil. Grande parte desta população começou a viver em áreas desprovidas de qualquer tipo de infraestrutura (MENDONÇA, 2004). A urbanização generalizada, que tipifica o atual estágio das metrópoles, torna as cidades altamente vulneráveis a riscos endógenos ou exógenos (DUBOISMAURY; CHALINE, 2004).

A literatura sobre a questão urbana no Brasil indica que a expansão das áreas periféricas está relacionada à procura por habitação em áreas com baixo pre- ço da terra, provocando um aumento das ocupações precárias, como favelas e loteamentos irregulares, em áreas sem infraestrutura e expostas a risco e à degradação ambiental (BONDUKI; ROLNIK, 1982; SMOLKA, 1993; MARICATO, 1996).

Dessa forma, a dinâmica de urbanização nas regiões periféricas, através da ocupação ilegal e predatória da terra urbana, faz com que grande parte das áreas de risco e proteção ambiental, tais como as margens dos cursos d'água, esteja ameaçada pelas ocupações precárias de uso habitacional de baixa renda, por absoluta falta de alternativas habitacionais, seja via mercado privado, seja via políticas públicas sociais (MARICATO, 2003).

\section{Tendências da periferia paulistana}

A lógica socioespacial da cidade de São Paulo está baseada em um modelo de ocupação urbana nitidamente polarizada e desigual. Desde a década de 1970, vem se intensificando, em São Paulo, o fenômeno da periferizacão, com incorporação de uma vasta área à mancha urbana da metrópole, muitas vezes pela ocupação de terras por loteamentos clandestinos e favelas.

O modelo de periferia, apontado pela sociologia urbana na década de 1970, atribuía ao Estado a responsabilidade pela reprodução da dinâmica capitalista; sendo o Brasil um país de capitalismo tardio, a periferia seria produto da acumulação econômica e da especulação imobiliária, ou seja, um aglomerado distante do centro, habitado pela crescente mão de obra necessária para o funcionamento da própria dinâmica da acumulação. Nessa ótica, a periferia consistia no espaço da espoliação urbana, quer dizer, da sistemática exclusão das classes trabalhadoras ao acesso aos serviços de consumo coletivo (KOWARICK,1980).

No caso da cidade de São Paulo, a progressiva ocupação do espaço urbano ocorre a partir da expansão da cidade em direção à periferia e aos municípios vizinhos, tendo-se delegado ao capital privado as providências relacionadas à ocupação do solo urbano, particularmente no que se refere à habitação e ao transporte.

Estudos realizados a partir dos anos 1990 indicam que houve ampliação dos serviços públicos, especialmente saneamento e educação básicos, atribuídos ao processo de redemocratização e à mudança das burocracias estatais com relação a algumas políticas públicas, quanto à pressão de movimentos sociais populares (MARQUES, 2000).

O expressivo crescimento demográfico e a expansão horizontal dessas áreas, na metrópole paulistana, têm contribuído para o aumento da heterogeneidade das periferias e para o crescimento da pobreza e vulnerabilidade social e ambiental. 
Nas três últimas décadas, os dois grandes eixos de expansão da cidade de São Paulo se canalizaram para as regiões leste e sul, sendo que esta última, inserida na área de proteção a mananciais, tem apresentado forte ritmo de crescimento, que se intensificou nos últimos anos (MEYER; GROSTEIN; BIDERMAN, 2004).

Para Torres e Marques (2001), a melhoria na oferta de equipamentos e serviços não impediu que uma acentuada parcela da população continuasse incluída de forma marginal no sistema econômico e submetida às piores condições de infraestrutura em espaços que os autores denominaram "hiperperiferias" e que representariam a "segregação da segregação", por conta da ausência de equipamentos e de oferta de serviços, menor renda da população, maior percurso para o trabalho e alta vulnerabilidade a riscos ambientais (inundações, desmoronamentos etc.). Estes elementos revelam o elevado grau de vulnerabilidade social e ambiental destas áreas hiperperiféricas e de fronteira urbana.

De acordo com a Fundação Sistema Estadual de Análise de Dados (SEADE, 2008), os padrões de expansão populacional observados nos últimos anos têm causado uma crescente pressão sobre as áreas de preservação ambiental e de proteção de mananciais, principalmente nos distritos de Parelheiros, Marsilac e Grajaú, situados na periferia da zona sul de São Paulo, acentuando-se a desigualdade ambiental em função da ocupação populacional desordenada nessas áreas.

A cidade de São Paulo, no espaço de tempo de apenas um século, passou de Metrópole do Café a Metrópole Industrial e, sucessivamente, a Metrópole da Era da Informação, apresentando, no século 21, reflexos de novos e graves problemas, muitos deles resultantes de profundas mudanças da economia globalizada (PINHO, 2005).

Como consequência do arrefecimento da fase industrial, muitas indústrias deslocaram-se para outros municípios, surgindo, em seu lugar, plantas industriais menores, automatizadas e não poluentes. Ampliou-se o trabalho informal (quase superando o trabalho formal, nos anos 2000) e acelerou-se a favelização da capital e de toda a Região Metropolitana de São Paulo, tornando mais visíveis as desigualdades sociais e a pobreza. Além disso, dada sua menor visibilidade frente às políticas públicas, as favelas de periferia mostravam-se muito menos estruturadas urbanisticamente e mais expostas às situações de risco ambiental.

A rápida evolução da tecnologia e do mercado eletrônico, entre outras mudanças tecnológicas, contribuiu para desvalorizar o trabalho não especializado, tendo como agravante a baixa escolaridade de significativa parte da população. Dessa forma, acentuaramse, nos primeiros anos do século 21 , desafios e con- trastes, dadas as novas demandas e necessidades de vida da metrópole, particularmente, nas áreas de saúde, educação, transporte, habitação e segurança.

A diversidade da luta pela terra e pela cidadania no Brasil sugere uma reflexão sobre as categorias presentes no quadro de uma exclusão social histórica com implicações etnorraciais. A marginalização urbana não se apresenta somente como recorte de classe social; as próprias formas de acesso à propriedade apontam para uma linha de exclusão racial.

Analisando indicadores socioeconômicos, Carril (2006) refere-se à correlação entre pobreza e moradia e entre cor e pobreza; observa-se elevada presença negra nas estatísticas de pobreza no Brasil, de modo que a segregação socioambiental nas periferias configura-se em marginalização socioespacial e racial: decorrido um século da abolição da escravatura, a população afrodescendente foi sendo empurrada para as áreas mais distantes das cidades, caracterizadas por extrema precariedade urbana.

No cenário urbano, o quilombo é recuperado pelas comunidades de rappers que procuram denunciar, através de novas formas de expressão e linguagem, a realidade socioespacial da periferia, retratando a falta de emprego, a ausência de saneamento, a perseguição policial, as escolas públicas incipientes.

\section{Perfil regional da periferia da zona sul}

Levantamentos da Fundação Sistema Estadual de Análise de Dados (SEADE, 2008) indicam que as áreas mais afastadas do centro da cidade são as que apresentam as maiores taxas de crescimento populacional, entre 2000 e 2008.

De acordo com o Seade, os padrões de expansão populacional observados nos últimos anos têm causado uma crescente pressão sobre as áreas de preservação ambiental e de proteção de mananciais. $\mathrm{O}$ crescimento populacional absoluto registrado na capital no período foi de, aproximadamente, $477 \mathrm{mil}$ pessoas, das quais $30 \%$ concentraram-se em Marsilac, Parelheiros e Grajaú, que contêm extensas áreas de proteção ambiental ou de mananciais, confirmando que "a extensão das periferias urbanas [...] tem sua expressão mais concreta na segregação espacial ou ambiental configurando imensas regiões, nas quais a pobreza é homogeneamente disseminada" (MARICATO, 2003,p. 152).

Essa colocação sintetiza o argumento relativo à homogeneidade das áreas periféricas das metrópoles brasileiras, que seriam marcadas pela sobreposição de múltiplas carências e privações, com conteúdos socioeconômicos bastante similares. A ideia de que os riscos sociais são cumulativos pode parecer bastante evidente para a maior parte dos observadores da cena urbana brasileira. 
No caso de São Paulo, o argumento teria sido comprovado por dezenas de estudos, principalmente, se considerarmos, a grande massa de dados existentes, bem como a sistemática produção de indicadores de cunho territorial, tais como o Indice de Desenvolvimento Humano (IDH), o Índice de Exclusão Social (SPOSATI, 1996), o Índice Paulista de Responsabilidade Social (IPRS) e outros. Vale ainda destacar que boa parte da literatura brasileira sobre a chamada "segregação socioespacial" tende a considerar que os riscos sociais, em geral, concentram-se espacialmente no anel externo das regiões metropolitanas. Essa visão associa-se com a caracterização das periferias urbanas como locais relativamente homogêneos, em termos de falta de investimentos públicos, de acesso a bens e serviços essenciais, além de indicadores socioeconômicos com maus resultados.

A partir dos conceitos apresentados, infere-se que as regiões localizadas na periferia da zona sul de São Paulo enquadram-se, perfeitamente, como áreas que sofreram um aumento da desigualdade ambiental, nas transformações urbanas recentes da cidade. Justificando essa afirmativa, será apresentado um breve perfil das regiões administrativas que a compõem, quais sejam: Campo Limpo, Capela do Socorro, M' Boi Mirim, Cidade Ademar e Parelheiros, utilizando dados da Pesquisa IRBEM 2011, divulgada pela Prefeitura Municipal de São Paulo.

Territorialmente, a zona sul ocupa $45,5 \%$ da cidade de São Paulo, numa área de $687 \mathrm{~km}^{2}$. O adensamento populacional é notório; dados da Secretaria de Planejamento Municipal (Seplan) atestam que, em 1991, a região contava com 2.961.713 habitantes, passando para 3.510.141, em 2005 (PREFEITURA MUNICIPALDE SÃO PAULO, 2011).

A região de Campo Limpo reúne os distritos periféricos de Campo Limpo e Capão Redondo, contendo 237 favelas; há 15 áreas de risco de desabamento, de forma que, em períodos de fortes chuvas, a região é assolada pelas enchentes de córregos, em função do despejo de entulho em locais irregulares. Déficit habitacional e enchentes são os grandes problemas da região; na falta de habitações adequadas, parte da população menos favorecida passa a viver em submoradias, à beira de córregos.

A região de Capela do Socorro é formada pelos distritos de Socorro, Cidade Dutra e Grajaú, ocupando uma área de $134 \mathrm{~km}^{2}$, que corresponde a 8,8\% do município, sendo que cerca de $90 \%$ de seu território está inserido em área de proteção aos mananciais. Os bairros que surgiram acompanharam o padrão periférico de expansão urbana que caracterizou o crescimento de São Paulo, particularmente nos anos 1970. Os arruamentos penetraram em áreas onde o solo é mais vulnerável à erosão e com altas declividades, inadequadas à urbanização. Sem dispor de infraestrutura urbana, de equipamentos soci- ais e distantes do transporte coletivo, grande número de trabalhadores autoconstruíram suas casas em lotes, na maioria das vezes ilegais, adquiridos através de longos financiamentos. O crescimento populacional é um importante indicador das transformações ocorridas na região: de 30 mil habitantes em 1960, Capela do Socorro passou a 261.230 em 1980 (crescimento de $773 \%$ ), e em 2000, para 563.922 (crescimento de $115 \%$ em relação a 1980). A partir de 1975 , a ocupação desta região passou a ser legalmente subordinada à Lei de Proteção dos Mananciais e à legislação de zoneamento industrial. Contudo, a legislação relativa aos mananciais foi insuficiente para conter o avanço da urbanização e a degradação ambiental da região, uma vez que os preços dos terrenos - praticamente excluídos do mercado imobiliário formal - tornaram-se extremamente baixos. A depreciação do valor da terra, aliada a outros fatores, como uma inadequada política habitacional, teve como efeito a expansão desenfreada de loteamentos clandestinos e de favelas, localizados em grande parte ao longo dos córregos contribuintes das represas. Estima-se a existência de cerca de 200 bairros irregulares e 220 favelas na região.

A história de M'Boi Mirim, que inclui os distritos de Jardim Ângela e Jardim São Luis, vincula-se ao desenvolvimento da região de Santo Amaro - polo de industrialização nos anos 1960. O processo de ocupação intensificou-se no auge do processo industrial, quando diversas vilas começaram a surgir na zona sul. Eram, na maioria, moradias dos operários que estavam chegando de vários estados e do interior paulista para trabalhar nas fábricas que se instalaram em Santo Amaro, até a explosão demográfica da região, a partir do fim da década de 1960, quando a ocupação tornou-se desordenada, inclusive em áreas de preservação de mananciais.

Em sua origem, Cidade Ademar era, praticamente, uma região dormitório, devido à explosão industrial de 1960. Seus bairros e vilas surgiram devido ao grande impulso do processo de urbanização, com loteamentos vendidos aos operários migrantes de diversas partes do Brasil em busca de trabalho. Até 1996, pertencia à região Administrativa de Santo Amaro e se constituía em periferia do seu centro urbano. Atualmente, a região caracteriza-se por ocupações e favelas, não havendo mais condições de expansão, já que existem poucas áreas disponíveis para moradia ou desenvolvimento de algum projeto habitacional.

No extremo sul da capital, ficam os distritos de Parelheiros e Marsilac, que compõem a subprefeitura de Parelheiros, ocupando uma área de $350 \mathrm{~km}^{2}$ cerca de $25 \%$ dos $1507 \mathrm{~km}^{2}$ de São Paulo, com muitas nascentes de água, que alimentam as represas Billings e Guarapiranga, responsáveis por 30\% do abastecimento da região metropolitana. Parelheiros 
apresentou um aumento significativo na taxa de crescimento demográfico: passou de 61.586 habitantes em 1991 para 111.240 habitantes em 2000 - o que representou um aumento de $80 \%$ na sua população. Segundo estimativas da Fundação Seade (2008), a região conta, atualmente, com um contingente populacional de 136 mil habitantes (um aumento de $20 \%$ em relação ao ano de 2000 ), sendo $60 \%$ pertencentes à zona rural. Por se tratar de área de mananciais, o solo não pode ser impermeabilizado, ou seja, suas vias não podem ser pavimentadas, assim como seus córregos não podem ser canalizados. A maioria das casas - construídas em loteamentos irregulares - despeja seus esgotos diretamente nos córregos, vulneráveis também ao acúmulo de lixo.

Os dados confirmam que o risco ambiental não se distribui de forma aleatória entre os diversos grupos sociais, mas segue os padrões de desigualdade e segregação social que marcam a estruturação das cidades. São exatamente as populações menos favorecidas, por características de renda, escolaridade, cor, gênero, que residem ou utilizam os territórios de maior vulnerabilidade ambiental que se superpõem à vulnerabilidade social.

Nesse contexto, a juventude merece atenção especial por seu potencial como força propulsora de ações coletivas em busca de sociedades mais humanas e equitativas.

\section{Vulnerabilidade social e vulnerabilidade juvenil}

O Mapa da Vulnerabilidade Social da População da Cidade de São Paulo ${ }^{1}$, desenvolvido na escala dos setores censitários, que destacou que a pobreza urbana no município, apresenta múltiplas dimensões. Estas não se restringem à simples carência (ou ausência) material, pois além da dimensão socioeconômica (baixos níveis de renda e escolaridade), também é importante considerar a dimensão demográfica da pobreza: entre os mais pobres, há composições familiares específicas, que devem ser consideradas com bastante cuidado, como famílias chefiadas por mulheres, por homens jovens de baixa escolaridade, compostas por muitas crianças, ou por pessoas idosas, entre outros aspectos.

A segregação observada em certos locais da cidade gera diferentes consequências perversas: menor acesso a serviços essenciais (devido as distâncias), maior exposição a certos tipos de agravos à saúde (condições de moradia insalubres), efeitos sobre a escolaridade dos jovens, menores oportunidades de mobilidade social (dada a maior fragilidade das redes de relações) etc. (TORRES; FERREIRA; GOMES, 2004).

É importante procurar compreender até que ponto determinados riscos sociais, especialmente aque- les que afetam indivíduos jovens, poderão, ou não, convergir para territórios urbanos específicos - de degradação ambiental, concentração do desemprego, violência urbana, baixo nível educacional e gravidez na adolescência, normalmente localizados nas periferias urbanas -, para discutir-se o efeito dessas relações sobre a incidência desses riscos.

$\mathrm{O}$ estudo desses tipos de riscos que afetam as populações mais jovens é particularmente relevante sob o ponto de vista das políticas sociais, especialmente se for considerado que a sobreposição de carências nessa faixa etária contribui para a reprodução de circuitos de pobreza.

Em relação a riscos juvenis, um dos principais exercícios empíricos sobre o tema foi o Índice de Vulnerabilidade Juvenil (IVJ), realizado pela Fundação Seade, em 2002, a partir de uma demanda da Secretaria Estadual da Cultura. Este estudo classificava os distritos administrativos da cidade em uma escala de 0 a 100 pontos, que expressava o grau de vulnerabilidade social dos seus jovens moradores, considerando, simultaneamente, os níveis de escolaridade, homicídios, fecundidade e outros. Esse estudo destacou a existência de cinco grupos de distritos no município, com distintos níveis de vulnerabilidade para os jovens ali residentes. Com poucas exceções, foram observadas coincidências espaciais entre os diversos tipos de riscos analisados, indicando - na escala de distritos - uma estreita relação existente entre condições socioeconômicas, em particular a pobreza, e situações de violência e maternidade entre os jovens residentes nestes locais. Assim, de certa forma, a hipótese do acúmulo de riscos foi também reafirmada por este exercício, realizado na escala do distrito (SEADE, 2002).

A partir dos dados do Censo Demográfico (IBGE, 2000) e do sistema de estatísticas vitais da Fundação Seade (2002), foram gerados quatro indicadores que expressam as condições de vida dos jovens no município de São Paulo: percentual de adolescentes do sexo feminino de 13 a 17 anos que já tiveram filhos, percentual de jovens de 18 a 19 anos com ensino médio completo, taxa de desemprego dos jovens de 18 a 24 anos e taxa de homicídio de homens de 18 a 29 anos. Os três primeiros indicadores foram derivados da amostra do Censo Demográfico, que é constituída por $10 \%$ das unidades domiciliares do município. A taxa de homicídios foi elaborada a partir da média dos óbitos para os anos de 1999, 2000 e 2001, sendo derivada do sistema de estatísticas vitais da Fundação Seade.

Estudos sobre padrões de segregação socioes-pacial em São Paulo constataram que a alta proporção de adolescentes numa determinada região correlacionase estreitamente à existência de pobreza nessa mesma região, o que, de certa forma, aponta para uma especificidade da realidade paulistana, pois em ou- 
tras cidades essa relação se dá com a presença de crianças e não com a de adolescentes (BOUSQUAT; COHN, 2003).

A construção do Mapa da Juventude de São Paulo baseou-se na elaboração do Indicador Composto Juvenil (ICJ), construído a partir de variáveis selecionadas com base nos resultados de pesquisas anteriormente realizadas pela Fundação Seade (Índice de Vulnerabilidade Juvenil, SEADE, 2002), pela PUC/Cedec (Mapa da Exclusão Social, SPOSATI, 1996) e pelo Cedec (Mapas de Risco da Violência, BOUSQUAT; COHN, 2003): Percentual da População Jovem do Distrito, Taxa Anual de Crescimento Populacional do Distrito entre 1991 e 2000, Percentual de Mães Adolescentes no Total de Nascidos Vivos, Coeficiente de Mortalidade por Homicídios na Faixa Etária de 15 a 24, Percentual de Jovens que Não Frequentam Escola, Coeficiente de Viagens por Motivo de Lazer, por Distrito, Índice de Mobilidade da População de 15 a 24 anos, Valor do Rendimento Médio Mensal Familiar.

Foi criado um ranking para cada variável, onde os distritos do município de São Paulo eram classificados do melhor para o pior resultado, cabendo ao melhor indicador a nota $1,0 \mathrm{e}$ ao pior, a nota 0 . Os distritos da periferia da zona sul - objeto de interesse desta pesquisa obtiveram as últimas colocações, ocupando os três últimos lugares do ranking: Parelheiros $(0,13)$, Grajaú $(0,14)$ e Jardim Ângela $(0,18)$. Os demais distritos também obtiveram índices muito baixos: Capão Redondo $(0,22)$,

Cidade Ademar (0,23), Marsilac (0,25), Jardim São Luís (0,25), Campo Limpo (0,3), Cidade Dutra (0,3).

A partir da definição do ICJ, os distritos foram agrupados em cinco Zonas Homogêneas, sendo que ZH1 é aquela que reúne melhores condições para os jovens, e a ZH5, as piores. A periferia da zona sul pertence à ZH5, o que significa que a população jovem da região em estudo enquadra-se numa condição de vulnerabilidade muito alta.

Assim sendo, cabe investigar as formas de expressão e de intervenção urbana desses jovens, seus valores, suas formas de sociabilidade, identidades e visão de mundo, articulados em seu espaço social.

\section{Culturas juvenis da periferia}

Segundo Magnani (2006), torna-se necessário pensar novas perspectivas teóricas e recortes analíticos que ajudem a explicar não só a produção socioespacial, mas também o processo que nela culminou, sem desconsiderar, entretanto, a atuação de movimentos culturais juvenis, que "por meio de elaborações estéticas articulam uma espécie de singularização da periferia, cuja novidade consiste na representação local ou nativa, e não de fora para dentro" (FRÚGOLI JR., 2005, p.114).

Há mais de 20 anos mesclando produção cultural e engajamento político, os artistas ligados ao hip $h o p^{2}$ despertaram o interesse acadêmico por terem sido pioneiros em produzir, coletivamente, discursos sobre a periferia a partir de interpretações dos mecanismos de marginalidade social e imprimi-los nas artes plásticas, na dança e na música. Assim, ao mesmo tempo em que essa estetização do espaço e cotidiano periféricos resultou em um discurso homogeneizante sobre práticas e problemas sociais - que se traduziu na máxima "periferia é periferia (em qualquer lugar)” (RACIONAIS MC'S, 1997) também trouxe à tona certa visão propositiva, segundo a qual "ser da periferia" significa participar de um estado de coisas, que inclui tanto uma capacidade para enfrentar as duras condições de vida, quanto

pertencer a redes de sociabilidade, a compartilhar certos gostos e valores.

Mas para além do hip hop, desde o início dos anos 1990, multiplicaram-se, no espaço urbano brasileiro, diferentes movimentos, grupos e projetos articulados em torno da periferia ou da favela, protagonizados por sujeitos que relacionam atuação e produtos artísticos a tais espaços e procuram explorar diferentes linguagens artísticas (como a música, o teatro, o cinema, as artes plásticas e a literatura). Essas ações se concretizam através de iniciativas organizadas em São Paulo por escritores identificados com a literatura marginal ou periférica, como o autodenominado movimento cultural 1daSul ("Somos todos um pela dignidade da zona sul"), criado em 1999, para promover atividades artísticas e criar bibliotecas comunitárias no distrito do Capão Redondo, e pela Cooperativa Cultural da Periferia (Cooperifa), que tem como principal atrativo a promoção de saraus semanais em um bar localizado na zona sul paulistana (NASCIMENTO, 2010).

Especificamente em São Paulo, esses diferentes projetos têm como importante espaço de divulgação de suas práticas a Agenda Cultural da Periferia (2011), uma publicação mensal produzida pelo Espaço de Cultura e Mobilização Social da ONG Ação Educativa, que veicula exclusivamente eventos promovidos nas periferias da Grande São Paulo por ar- 
tistas periféricos ou as apresentações destes no centro da capital paulistana.

A Semana de Arte Moderna da Periferia, realizada em 2007, reuniu cerca de 300 artistas ligados a grupos de literatura, teatro, dança, música e produtoras/coletivos de cinema, numa série de atividades artísticas que mobilizou unidades escolares e centros culturais da zona sul de São Paulo (COOPERIFA, 2007).

Esses exemplos sugerem articulações entre cultura e política no cenário urbano, com novas questões e demandas que transcendem as tradicionais como infraestrutura e serviços, requerendo políticas culturais específicas e estabelecendo conexões entre os jovens afrodescendentes das periferias e a sociedade midiática.

\section{Conclusão}

A juventude constitui-se em importante questão enquanto desafio ao desenvolvimento, nos países latino-americanos, em termos de vulnerabilidade social.

A violência e a degradação urbana são as manifestações mais visíveis da segregação socioambiental - que, além de agravar o distanciamento entre as classes sociais, promove uma espécie de confinamento dos pobres, acentuando a percepção da vulnerabilidade. A violência, tendo os jovens como vítimas ou agentes, está relacionada à condição de vulnerabilidade social, dado o mecanismo de exclusão que tende a concentrar e distanciar a pobreza do sistema social, enquanto impede o seu acesso a recursos materiais fundamentais.

Os moradores das favelas e dos loteamentos clandestinos constituem a maioria da população paulistana. Conforme colocado por Kowarick e Bonduki (1994), é a ilegalidade ou clandestinidade em face de um ordenamento jurídico-institucional que, desconhecendo a realidade social desta maioria, nega o acesso aos benefícios urbanos básicos. Configura, deste modo, um processo socioeconômico e político que gera uma concepção de ordem excludente, decretando, com isso, uma condição de subcidadania.

A segregação socioambiental observada na periferia da zona sul de São Paulo produz diferentes consequências negativas, tais como: menor acesso a serviços essenciais, maior exposição a riscos de saúde, maior propensão à violência e menores chances de mobilidade social.

Além disso, a análise dos efeitos sobre a escolaridade dos jovens revela que estudar em escolas de áreas periféricas, nas quais a maioria dos alunos tem baixa renda e pais com baixa escolaridade, apresenta resultados significativamente negativos sobre o desempenho escolar, que irão se refletir no acesso às estruturas de oportunidades.
O potencial dos jovens da periferia da zona sul de São Paulo expressa-se através de suas demandas, preferências e dificuldades: de acesso à educação, lazer, saúde, trabalho, entre outras, juntando-se em grupos específicos - musicais, teatro, grafite, folclore, ou até mesmo grupos de anarquistas, vegetarianos radicais e evangélicos - como manifestação própria dos jovens da periferia excluída, numa elaboração da sua realidade social.

\section{Referências}

AGENDA CULTURAL DA PERIFERIA. Ano 5, n. 50, Out. 2011. Disponível em: <http://www.acaoeducativa .org.br/ agendadaperiferia $>$. Acesso em: 16 jul. 2011.

BONDUKI, N.; ROLNIK, R. Periferia da Grande São Paulo: reprodução do espaço como expediente de reprodução da força de trabalho. In: MARICATO, E. (Org.). A produção capitalista da casa (e da cidade) do Brasil industrial. São Paulo: Alfa-Ômega, 1982, p. 117-154.

BOUSQUAT, A.; COHN, A. A construção do mapa da juventude de São Paulo. Lua Nova, revista de cultura e política, n. 60, p. 8196, 2003.

CARRIL, L. Quilombo, favela e periferia: a longa busca da cidadania. São Paulo: Anablumme, 2006.

CASTELS, M. A questão urbana. São Paulo: Paz e Terra, 1983.

COOPERIFA. Disponível em: <http://cooperifa.blogspot.com/ 07/11/2007>. Acesso em: 2 ago. 2011.

DUBOIS-MAURY, J.; CHALINE, C. Les risques urbains. Paris: Armand Colin, 2004.

FRÚGOLI JR., H. O urbano em questão na antropologia: interfaces com a sociologia. Revista de Antropologia, São Paulo, v. 48, n. 1, p. 107-124, jan./jun. 2005.

IBGE- Instituto Brasileiro de Geografia e Estatística. Censo 2000. Disponível em: 〈http://www.ibge.gov.br/censo/divulgacao.shtm〉. Acesso em: 10 set. 2011.

KOWARICK, L. Capitalismo e marginalidade na América Latina. Rio de Janeiro: Paz e Terra, 1980.

KOWARICK, L.; BONDUKI, N. Espaço urbano e espaço político: do populismo à redemocratização. In: KOWARICK, L.; ANT, C. (Org.). As lutas sociais e a cidade. São Paulo: passado e presente. Rio de Janeiro: Paz e Terra, 1994, p. 152.

LOURENÇO, M. L. Cultura, arte, política e o movimento hip hop. Curitiba: Chain, 2002. 
MAGNANI, J. G. C. Trajetos e trajetórias: uma perspectiva da antropologia urbana. Sexta-feira, São Paulo: Ed. 34, n. 8, p. 3043, 2006.

MARICATO, E. Metrópole na periferia do capitalismo: ilegalidade, desigualdade e violência. São Paulo: Hucitec, 1996.

Metrópole, legislação e desigualdade. Estudos Avançados, São Paulo, v. 17, n. 48, p. 151-166, ago. 2003.

MARQUES, E. C. Estado e redes sociais: permeabilidade e coesão nas políticas urbanas do Rio de Janeiro. Rio de Janeiro: Revan/Fapesp, 2000

MENDONÇA, F. Risks, Vulnerability and Urban SocioEnvironmental Approach: a Reflection on the CMA and Curitiba. Revista Desenvolvimento e Meio Ambiente, Curitiba: Editora UFPR, n. 10, p. 139-148, jul./dez. 2004.

MEYER, R.; GROSTEIN, M.; BIDERMAN, C. São Paulo metrópole. São Paulo: Edusp, 2004

NASCIMENTO, É. P. A periferia de São Paul: revendo discursos, atualizando o debate. RUA, n. 16, v. 2, 2010. Disponível em: <http://www.labeurb.unicamp-.br/rua/pages/home/ lerArtigo.rua?id=96\&pagina=8 $>$. Acesso em: 12 set. 2011.

PINHO, D. B. Jovens da periferia da capital paulista: arte, cooperação e inclusão social. Disponível em: $\langle\underline{h t t p: / /}$ www.econ.fea.usp.br/seminarios/2005 1/diva pinho.pdf $>$. Acesso em: 15 ago. 2011.

PREFEITURA MUNICIPAL DE SÃO PAULO. Pesquisa IRBEM 2011. Indicadores de Referência de Bem-Estar no Município. Rede Nossa São Paulo/ IBOPE, 2011. Disponível em: <http://www.nossasaopaulo.org.br/portal/arquivos/PesquisaIRBEM-Ibope-2011.pdf $>$. Acesso em: 5 ago. 2011.

RACIONAIS MC'S. Álbum 1997. Sobrevivendo no Inferno. Periferia é periferia (em qualquer lugar). Disponível em: <http:/ /www.youtube.com/watch? $\mathrm{v}=\mathrm{XF} 3 \mathrm{BdFJKrgw}>$. Acesso em: 20 jul. 2011.

SEADE- Fundação Sistema Estadual de Análise de Dados. Índice de Vulnerabilidade Juvenil. 2002. Disponível em: 〈http:// www.seade.gov.br>. Acesso em: 30 jul. 2011.

Atualização dos dados censitários de favelas e loteamentos irregulares de São Paulo, Relatório Analítico, 2008. Disponível em: 〈http://www.habisp.inf.br >. Acesso em: 1 ago. 2011.

SMOLKA, M. Meio ambiente e estrutura urbana. In: MARTINE, G. (Org.). População, meio ambiente e desenvolvimento: verdades e contradições. Campinas: Editora da Unicamp, 1993, p. 133-148.

SPOSATI, A. Mapa de exclusão/inclusão da Cidade de São Paulo. São Paulo: Educ, 1996.
TELLA, M. A. P. Atitude, arte, cultura e autoconhecimento: o rap como voz da periferia. 2000. 229 f. Dissertação (Mestrado em Sociologia) - Pontifícia Universidade Católica de São Paulo, São Paulo, 2000.

TORRES, H; FERREIRA, M.; GOMES, S. Educação e segregação social: explorando o efeito das relações de vizinhança. In: MARQUES, E.; TORRES, H. (Org.). São Paulo: segregação, pobreza e desigualdades sociais. São Paulo: Editora Senac, 2004 , p. $123-142$.

TORRES, H.; MARQUES, E. Reflexões sobre a hiperperiferia: novas e velhas faces da pobreza no entorno metropolitano. Revista Brasileira de Estudos Urbanos e Regionais, n. 4, 2001, p. 49-70.

\section{Notas}

1 Este mapeamento das áreas de vulnerabilidade do município de São Paulo baseou-se em variáveis selecionadas do Censo Demográfico 2000, que, submetidas à análise fatorial, foram agrupadas em duas dimensões principais, denominadas "dimensão de privação socioeconômica" e "dimensão de ciclo de vida familiar"; estas dimensões combinadas, por meio de análise de cluster, deram origem a diferentes grupos de vulnerabilidade social (PREFEITURA MUNICIPAL DE SÃO PAULO, 2011).

2 A cultura hip hop surgiu nos Estados Unidos, na década de 1970, forma de expressão coletiva, abrangendo manifestações artísticas nos campos da música (RAP, sigla derivada de rhythm and poetry - ritmo e poesia, uma espécie de canto falado ou fala rítmica), das artes visuais (grafite) e da dança (break). O movimento chegou ao Brasil em meados dos anos 1980, época de sensível aumento da população pobre do país, consequência do agravamento da crise econômica que marcou o período da redemocratização (CARRIL, 2006; LOURENÇO, 2002; TELLA, 2000).

\section{Elizabeth Borelli}

eborelli@ pucsp.br

Doutorado em Ciências Sociais pela Pontifícia Universidade Católica de São Paulo (PUC-SP)

Participa do Curso Post-Doctoral promovido pelo Consejo Latinoamericano de Ciencias Sociales (Clacso) em articulação com outras quatro instituições latino-americanas Professora na PUC-SP

\section{PUC-SP}

Faculdade de Economia e Administração Departamento de Atuária e Métodos Quantitativos Rua Monte Alegre, 984

São Paulo - São Paulo CEP: 05014-901 